\title{
PELATIHAN ANIMASI 3D DENGAN ICLONE 6 UNTUK SISWA BERKESULITAN BELAJAR
}

\author{
Ruby Chrissandy ${ }^{1}$ dan Ferdy Tanumihardja ${ }^{2}$ \\ ${ }^{1}$ Program Studi Desain Komunikasi Visual, Universitas Tarumanagara Jakarta \\ Email:rubyc@fsrd.untar.ac.id \\ ${ }^{2}$ Program Studi Desain Komunikasi Visual, Universitas Tarumanagara Jakarta \\ Email: ferdit@ fsrd.untar.ac.id
}

\begin{abstract}
ABSTRAK
Sekolah Talenta di bawah Yayasan Peduli Anak Spesial (YPAS) fokus pada pendidikan bagi Anak Berkesulitan Belajar atau dalam bahasa Inggris disebut Learning Disability. Arah pendidikannya diarahkan pada pengembangan potensi dan bakat siswa di bidang seni dan dikemas dalam kurikulum Sekolah Kejuruan Seni Rupa dan Desain. Saat ini mereka belum memiliki program pembelajaran animasi 3D untuk siswa, maka Fakultas Seni Rupa dan Desain UNTAR membantu dengan memberikan pelatihan animasi $3 D$ dengan iClone 6 . Metode pelaksanaannya dengan perancangan pelatihan dasar animasi yang dilaksanakan di studio animasi FSRD UNTAR dan pembuatan modul. Hasilnya peserta pelatihan mampu mengikuti instruksi yang diberikan saat mempelajari software tersebut.
\end{abstract}

Kata kunci: animasi 3D, iClone 6, siswa berkesulitan belajar, learning disability, Yayasan Peduli Anak Spesial.

\section{PENDAHULUAN}

Yayasan Peduli Anak Spesial dibentuk berdasarkan kegelisahan beberapa orang tua murid Anak Berkesulitan Belajar (ABB) yang akan melanjutkan pendidikannya ke jenjang Sekolah Menengah Atas. Akhirnya berdiri sekolah Talenta dengan jenjang satuan pendidikan SD, SMP SMA untuk kebutuhan ABB. Sekolah Talenta merupakan sekolah khusus bagi Anak Berkesulitan Belajar (ABB). Visinya mewujudkan system pendidikan bagi Anak Berkesulitan Belajar (ABB) sesuai dengan tujuan pendidikan nasional sehingga ABB mampu berpartisipasi aktif di tengah masyarakat. Misinya melaksanakan program bagi ABB berdasarkan kurikulum berbasis perkembangan minat dan bakar siswa. Kurikulum Sekolah Talenta mengacu pada kurikulum sekolah regular tetapi isi materi dan metode disiapkan sesuai kebutuhan ABB. Khusus pendidikan SMA diarahkan pada pengembangan potensi dan bakat siswa di bidang seni dan di kemas dalam kurikulum Sekolah Kejuruan Seni Rupa dan Desain.

Peserta didik Sekolah Talenta masuk kategori Anak Berkebutuhan Khusus (ABK) di mana ada beberapa istilah yang digunakan lembaga/organisasi dalam menyebutkan anak berkebutuhan khusus, pada modul kelas inklusi UNESCO disebutkan anak-anak dengan disabilitas. Definisi kecacatan masih menjadi perdebatam antara kelompok-kelompok cacat dan pemerhati kecacatan, contoh orang yang terganggu pendengarannya menggunakan bahasa isyarat untuk komunikasi dan tidak mau didefinisikan kelompok cacat. Ada yang menyukai disebut difabel / kemampuan yang berbeda dalam bahasa Inggris disebut different ability. Perdebatan juga berlanjut pada istilah impairment (kelainan), disability (kecacatan), dan handicap (handicap). The World Health Organization (WHO) telah mendefinisikan kelainan, kecacatan dan handicap seperti berikut: Ketunaan / Kelainan adalah kehilangan yan gtemporer atau permanan atau keabnormalan dari struktur atau fungsi tubuh, baik fisiologi atau psikologis. Kenetranaan/kelainan adalah sebuah gangguan yang mempengaruhi fungsi baik mental (ingatan, kesadaran) atau indera, internal (jantung, ginjal), atau eksternal (kepala, batang tubuh atau kaki tangan). Disabilitas / kecacatan adalah keterbatasan atau ketidakmampuan untuk melakukan aktifitas dengan cara atau di dalam 
rentang yang dianggap normal untuk manusia, yang pada umumnya disebabkan kelainan. Handicap adalah kelainan atau kecacatan yang membatasi atau menghalangi pemenuhan satu atau beberapa peran yang dianggap normal, tergantung pada jenis kelamin, usia, dan factor budaya (UNESCO: 2009:, hal 16). ABB sendiri didefinisikan sebagai seseorang yang tidak normal dalam belajar atau disebut mengalami kesulitan belajar (learning disability/LD) didefinisikan menurut National Advisory Committee on Handicapped Children adalah satu atau gangguan proses psikologi dasar yang melibatkan pemahaman dan penggunaan bahasa, lisan atau tulisan, yang dapat memanifestasikan dirinya dalam kemampuan yang tidak sempurna untuk mendengarkan, berpikir, berbicara, membaca, menulis, mengeja, atau melakukan perhitungan matematis (Erin, J. N, 1997: 310). LD juga mengalami masalah pada belajar dan masalah perhatian sehingga membuat masalah akademik dan emosional perlu diatasi (Handwerk, M. L, 1998: 337). Menurut LD Online Learning Disability adalah gangguan neurologis diakibatkan oleh perbedaan cara otak seseorang terhubung. Anak ini memiliki kemampuan belajar yang baik atau cenderung lebih pintar dari teman sebayanya tetapi mereka mungkin mengalami kesulitan membaca, menulis, memberi ejaan, penalaran, mengingat dan/atau mengajur informasi jika dibiarkan memikirkan semuanya sendiri atau jika diajarkan dengan cara konvensional. Ada beberapa bentuk kesulitan belajar, yaitu; disleksia adalah kecacatan berbasis bahasa di mana seseorang sulit memahami kata-kata tertulis. Ini juga bisa disebut sebagai ketidakmampuan membaca atau gangguan membaca. Diskalkulia adalah kesulitan berhitung atau mengalami kesulitan dalam memecahkan masalah aritmatika dan memahami konsep matematika. Disgrafia adalah kesulitan menulis, seseorang merasa sulit untuk membentuk huruf atau menulis dalam ruang yang ditentukan. Disorder adalah gangguan pemrosesan auditori dan visual atau ketidakmampuan sensorik di mana seseorang sulit memahami bahasa meskipun pendengaran dan penglihatan normal. Ketidak mampuan belajar nonverbal adalah gangguan neurologis yang berasala dari otak kanan, menyebabkan masalah dengan fungsi pemrosesan visual spatial, intuitif, organisasional, evaluative dan holistic. (http://www.ldonline.org/ldbasics/whatisld, 1 Agustus 2017).

Peserta didik Sekolah Talenta pernah mendapatkan penghargaan kompetisi Seni Internasional yang diberikan Duta Besar Republik Ceko. Karya-karya seni mereka diwujudkan dalam bentuk souvenir sekolah seperti baju dan cangkir, hal ini merupakan apresiasi pihak sekolah terhadap karya peserta didik mereka. Saat ini Sekolah Talenta memiliki kegiatan intrakulikuler seperti musik, vokal, fotografi, komputer grafis dan seni rupa. Untuk siswa SMA kelas 3 atau tingkat akhir ditingkatkan kemampuannya sesuai minat para siswa dan diharapkan mereka bisa melanjutkan pendidikan di perguruan tinggi. Sekolah Talenta saat ini belum memiliki program pembelajaran animasi 3D untuk para siswanya. Program pelatihan materi animasi belum pernah dilakukan di sekolah Talenta. Para siswa memerlukan saluran untuk berkarya, mereka sudah mendapatkan materi fotografi, seni lukis dan computer grafis. Untuk membantu siswa yang memiliki peminatan animasi maka diperlukan pelatihan software animasi.

Fakultas Seni Rupa dan Desain (FSRD) dengan program studi Desain Komunikasi Visual (DKV) memiliki kemampuan dalam bidang audio visual dan animasi dan dapat menjadi lembaga yang membantu dalam memberikan pelatihan animasi. DKV memiliki mata kuliah animasi yang mengajarkan animasi dengan menggunakan software iClone. Software ini dapat digunakan untuk keperluan previz, membuat film pendek, dan membuat game. Untuk itu maka diselenggarakan kegiatan "Pelatihan Animasi 3D dengan iClone 6 Untuk Anak Berkesulitan Belajar", guna meningkatkan kemampuan ABB dengan pengetahuan animasi. Dengan menguasai software iClone, diharapkan mereka dapat mengembangkannya menjadi karya previz, film animasi, atau game. 
Kegiatan ini dilaksanakan sebagai kegiatan pengabdian kepada masyarakat yang dilakukan oleh dosen, dan mahasiswa Fakultas Seni Rupa dan Desain Universitas Tarumanagara program studi Desain Komunikasi Visual. Kolaborasi keduanya diharapkan dapat memberikan kontribusi dalam mempelajari animasi lewat software iClone 6. Program ini diharapkan dapat menjadi dukungan terhadap pendidikan untuk Anak Berkesulitan Belajar (ABB). Untuk masa yang akan datang kegiatan ini diharapkan dapat dikembangkan lebih lanjut pada berbagai materi pelatihan lainnya.

Fakultas Seni Rupa dan Desain Universitas Tarumanagara saat ini telah memiliki Mahasiswa berkebutuhan khusus, ada yang tuna rungu dan ADHD. Dengan pengalaman ini FSRD UNTAR ingin berbagi kepada anak-anak berkebutuhan khusus pengetahuan materi animasi agar mereka bisa mengoperasikan software iClone untuk membuat karya animasi 3D. Materi ini berdasarkan kurikulum di Desain Komunikasi Visual (DKV) di mata kuliah animasi. Pengertian animasi 3D adalah proses digital pembuatan dan manipulasi gambar bergerak pada dimensi ruang 3 dimensi yang memiliki bentuk, volume, dan ruang.

Software iClone adalah perangkat lunak animasi 3D yang memadukan penciptaan karakter, animasi, desain adegan dan cerita sinematik. Perangkat ini menciptakan alur kerja animasi sebagai alat 3D dan mesin game standar untuk aplikasi interaktif, produksi film dan virtual. IClone telah banyak digunakan oleh pembuat film,kru pro studio, tim previz, penulis, sutradara, animator, pengiklan, dan siapa saja yang ingin memvisualkan idenya menjadi kenyataan dalam bentuk 3D. Perangkat ini juga dilengkapi dengan 3DXchange yang berfungsi mengimpor dan mengekspor semua jenis asset 3D, termasuk objek statis, props animasi, karakter dengan skinboned rigged dan file gerakan. Perangkat ini bisa mengadaptasi file dari Maya, Blender, Cinema4D dan Daz Studio. Hal ini membuat iClone menjadi alat yang sangat penting untuk desain game dan alur kerja CG.

\section{METODE PELAKSANAAN PKM}

Permasalahan Sekolah Talenta untuk memberikan materi animasi 3D karena keterbatasan fasilitas maka DKV UNTAR memfasilitasi pelatihan animasi 3D dengan iClone 6 dengan tujuan meningkatkan pengetahuan animasi 3D bagi ABB. Metode pelaksanaan kegiatan dirancang sesuai dengan urutan sebagai berikut: Pengumpulan data permasalahan Sekolah Talenta, perancangan pelatihan animasi 3D iClone 6, pembuatan modul pelatihan animasi 3D iClone 6 , dan pelaksanaan pelatihan untuk ABB yang dilaksanakan di FSRD UNTAR gedung K it 5 ruang studio animasi.

\section{HASIL DAN PEMBAHASAN}

Acara pelatihan dilaksanakan hari Rabu 29 November 2017, diawali registrasi, pembukaan, materi sesi pertama penjelasan software iClone 6 berupa tampilan window iClone 6 , camera tools, tansform tools, interface tools. Materi sesi kedua peserta diajarkan bagaimana membuat, mengembangkan karakter dan properti. Goal dari pelatihan ini peserta dapat membuat project setup, setting karakter yang ada di template, dan mengatur setting render video.

Pada dasarnya software iClone 6 memiliki empat docking areas, pertama area atas yang berisi semua toolbars seperti project, general, camera, dan physics, kedua area bawah atau timeline dengan isinya track menu lists, edit, break, loop, speed, add key, play/pause/stop, ketiga area 
kanan dan kiri berisi content manager, scene manager, modify, preference, project settings, visual settings, mini viewport, plug in panel, dan keempat area tengah berisi preview window. Di sesi pertama peserta diminta untuk membuat defaults project $(\mathrm{menu}>$ file $>$ new project $(\mathrm{Ctr}+\mathrm{N})$, dilanjutkan dengan memilih karakter yang ada di content manager (click content manager/F4>actor tav>template>actor template>avatar>01_G6 character Heidi/Mason), eksplorasi karakter dengan scene manager $>$ avatar (condition) $>$ light (condition) $>$ image layer (condition).

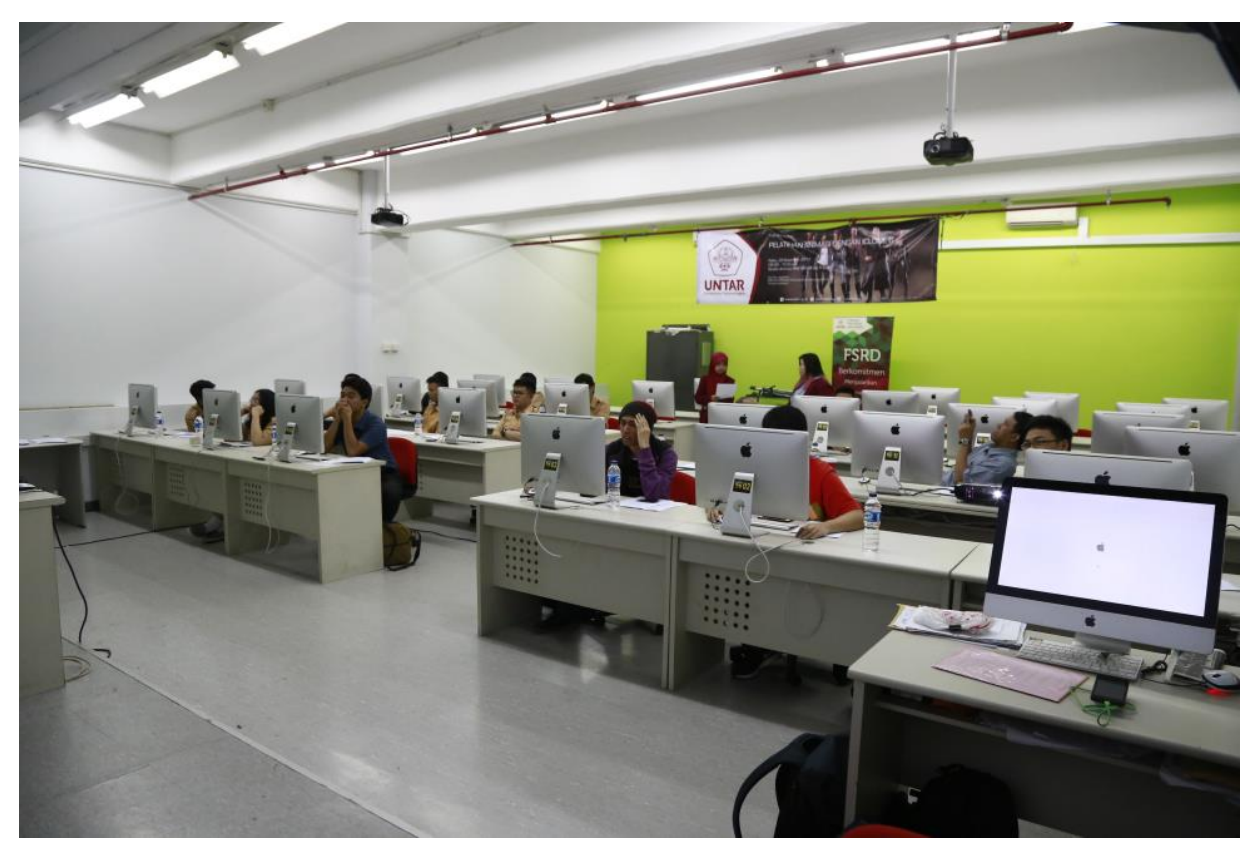

Gambar 1. Studio animasi dari FSRD dijadikan tempat pelatihan karena memiliki fasilitas yang cukup memadai.

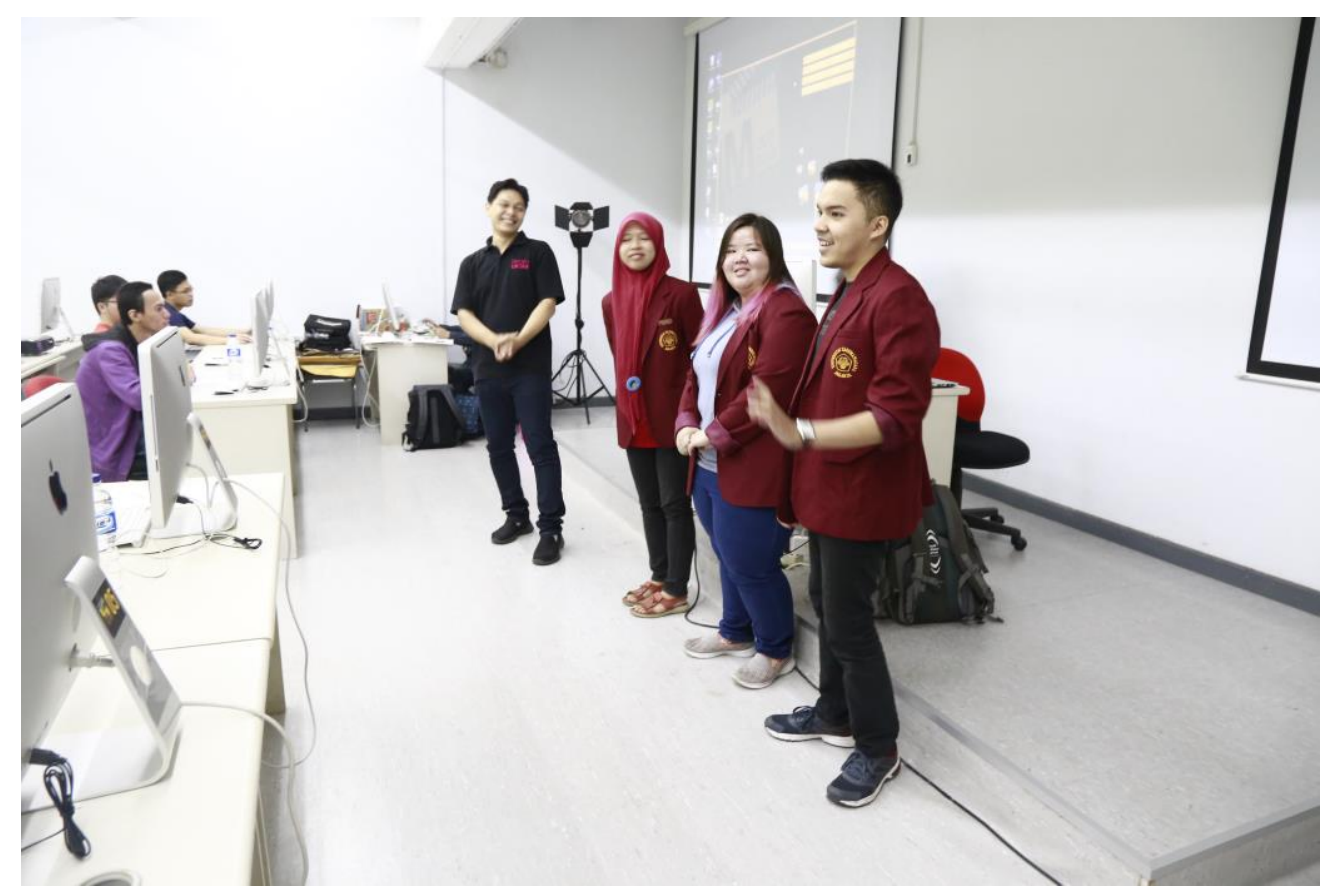

Gambar 2. Workshop ini didampingi mahasiswa DKV UNTAR. 


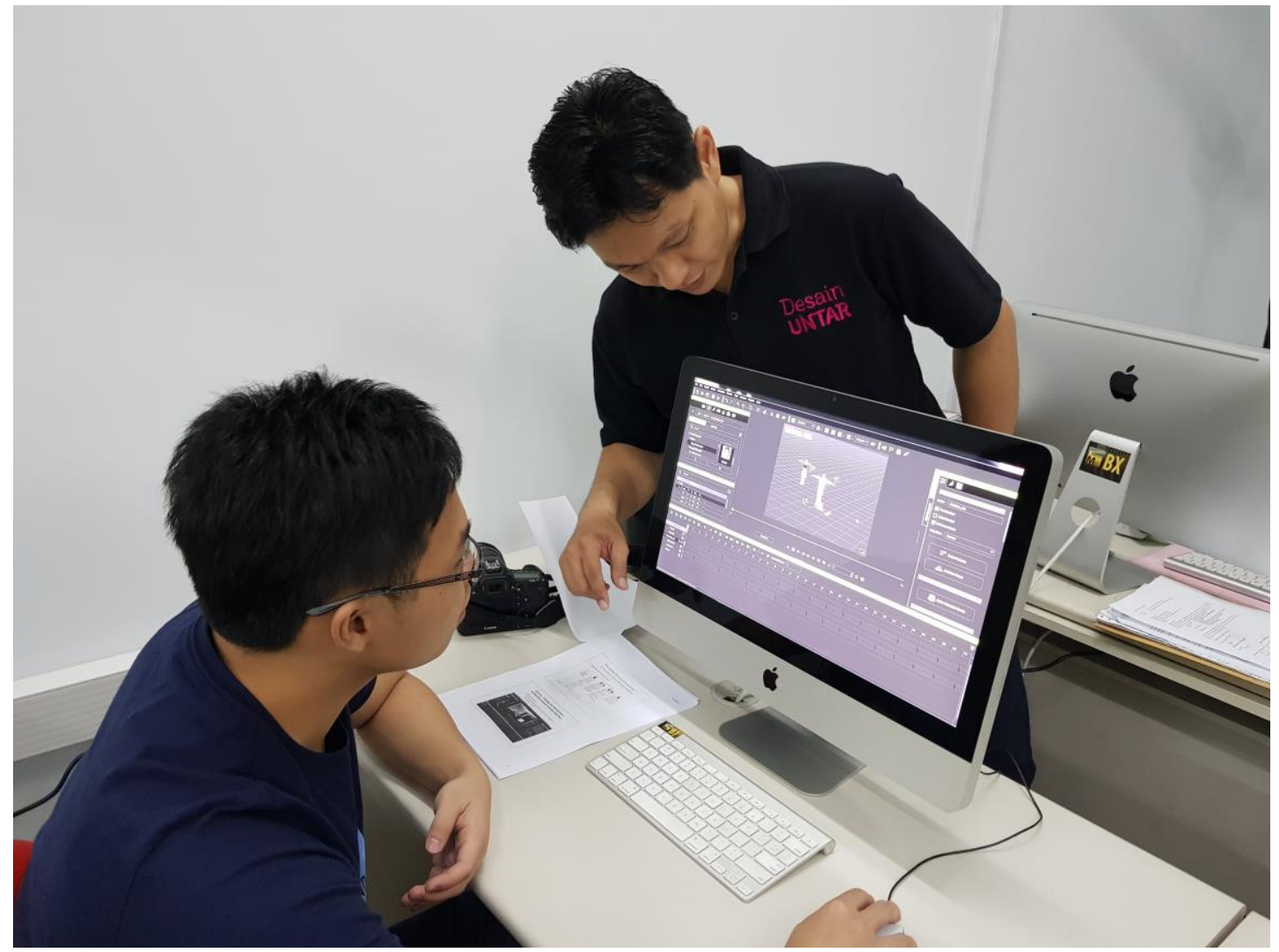

Gambar 3. Ruby Chrissandy membantu siswa menggunakan tools yang ada di iClone 6.

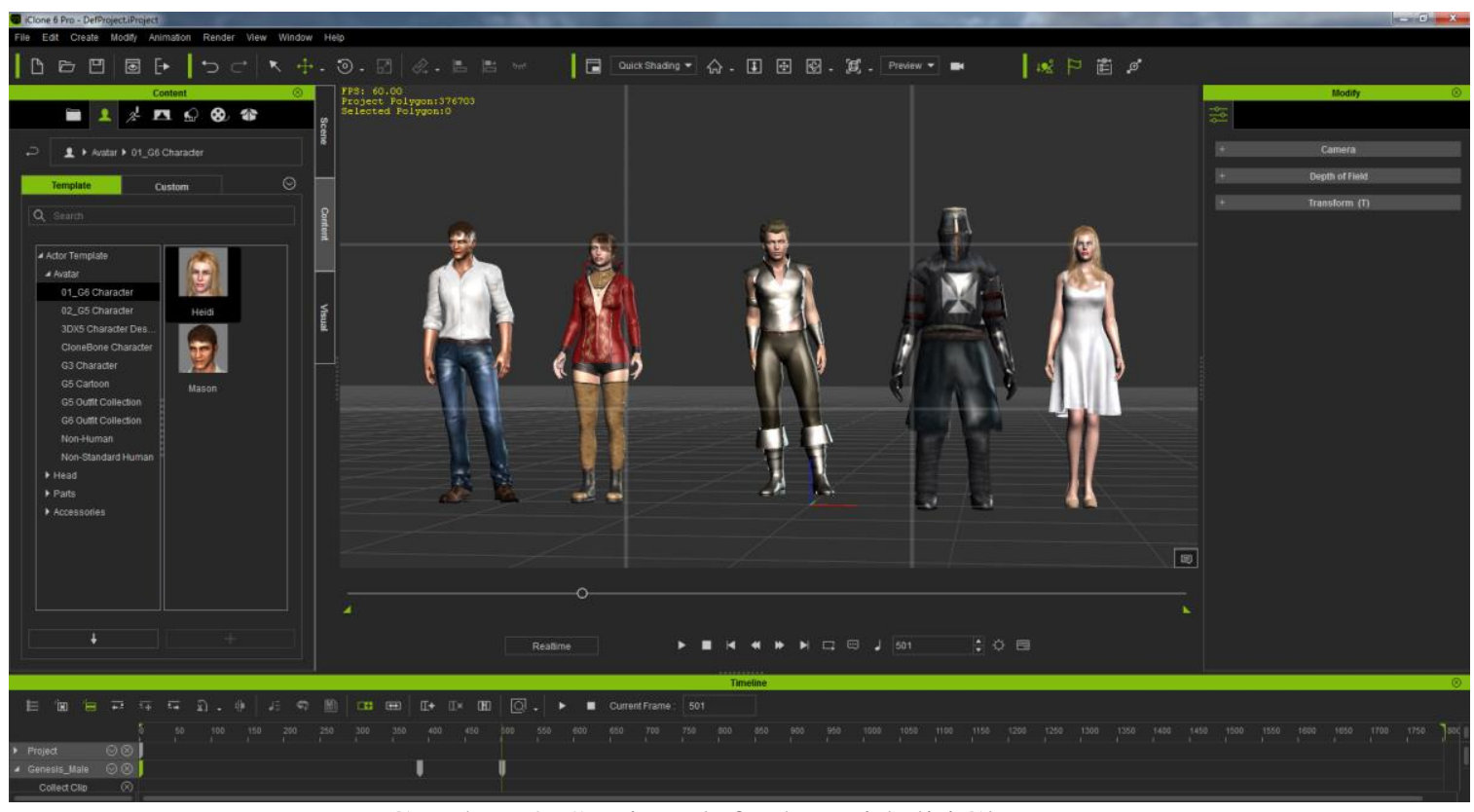

Gambar 4. Setting defaults grid di iClone 6. 


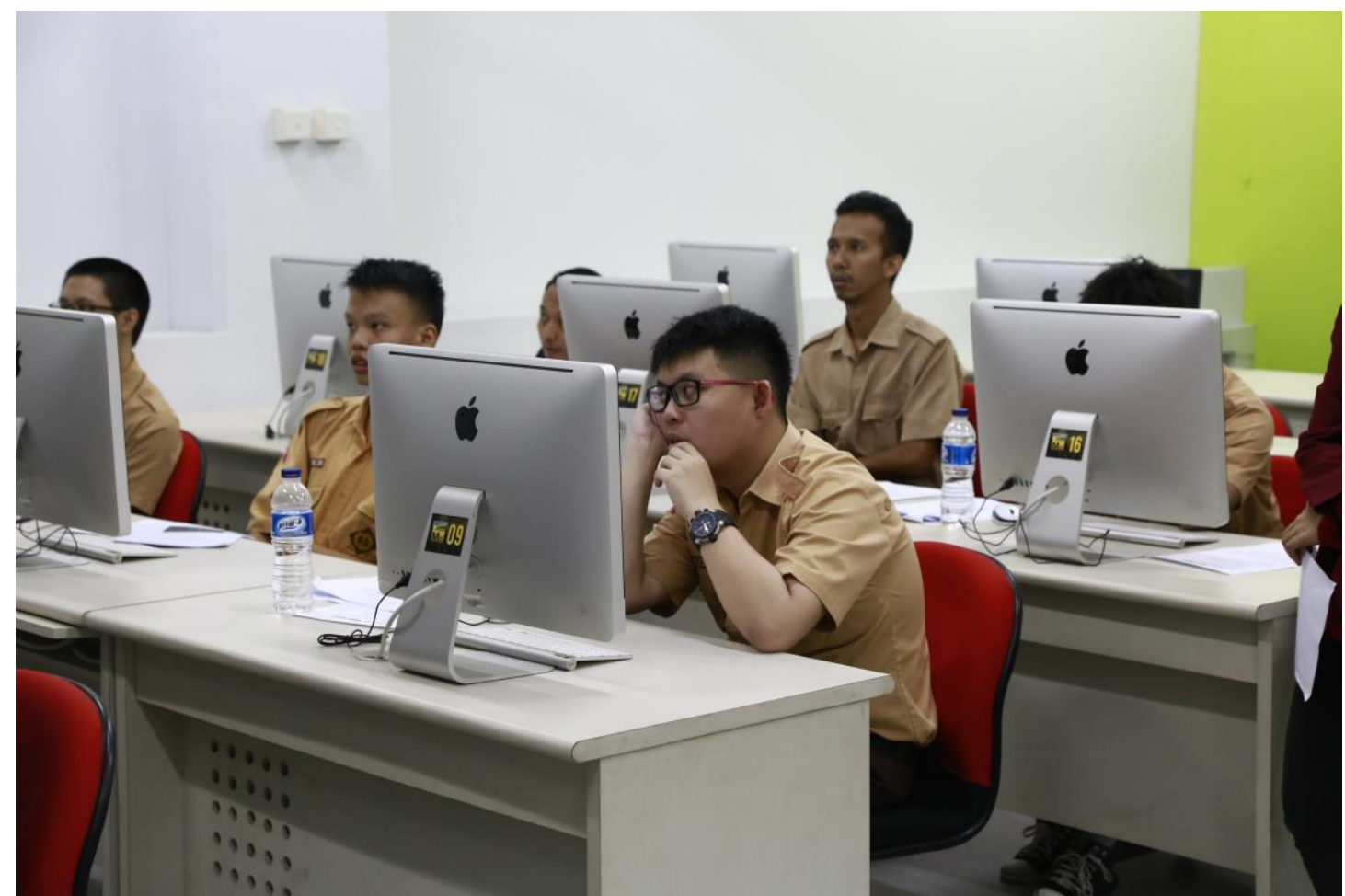

Gambar 5. Para peserta sangat tertarik mempelajari materi workshop sampai selesai.

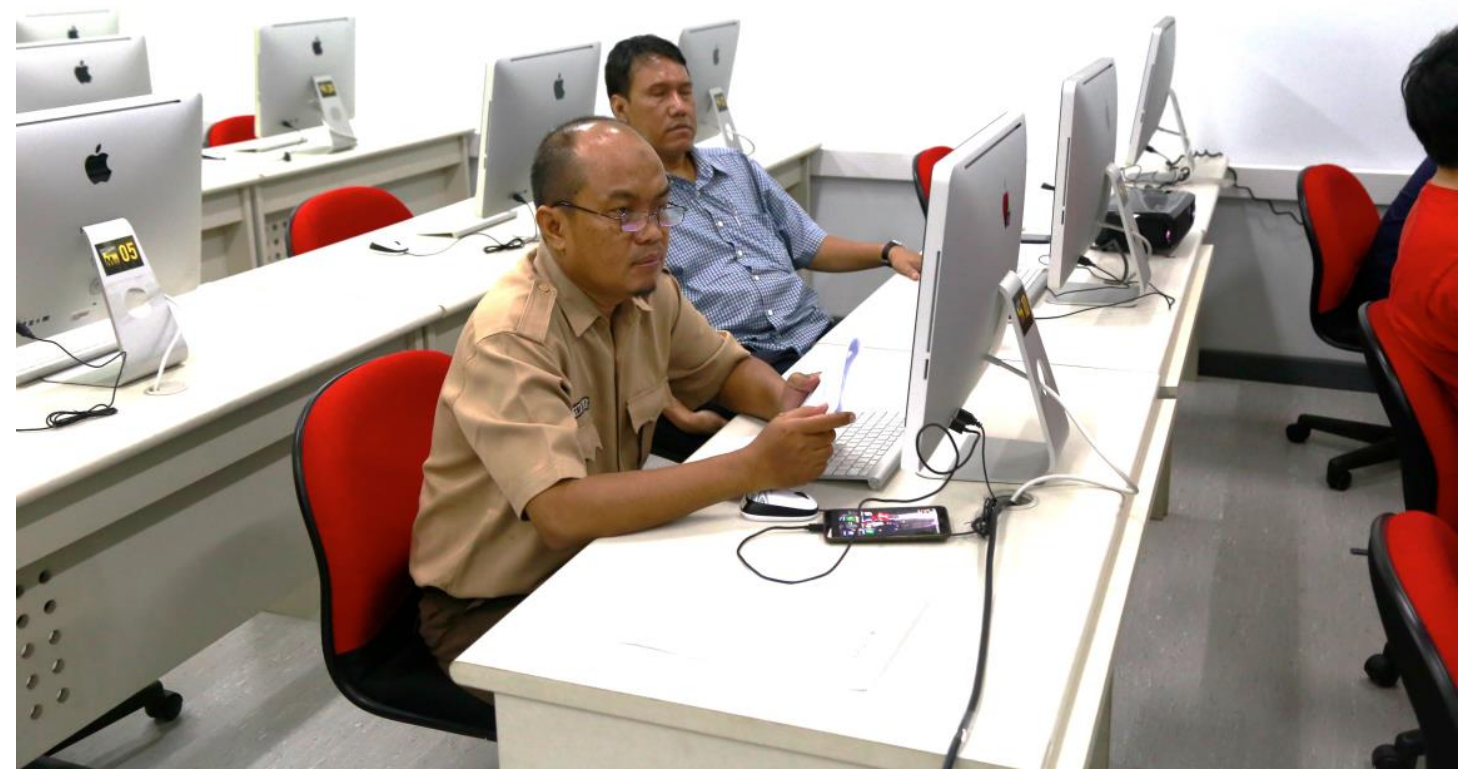

Gambar 6. Kegiatan ini dikuti oleh kepala sekolah Talenta, guru dan siswa. 


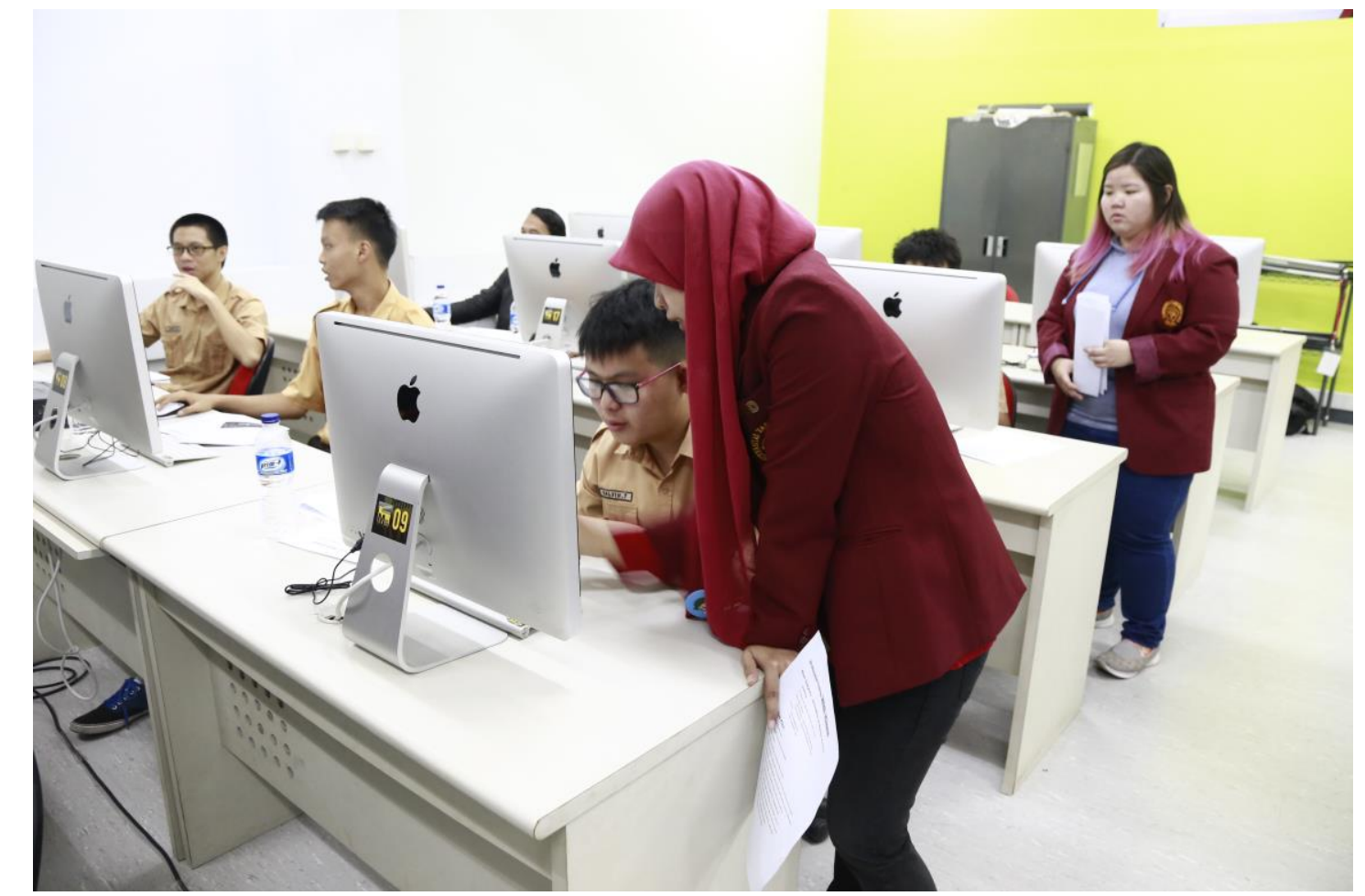

Gambar 7. Mahasiswa DKV UNTAR memiliki wawasan penggunaan software iClone karena sudah mempelajarinya dari mata kuliah animasi.

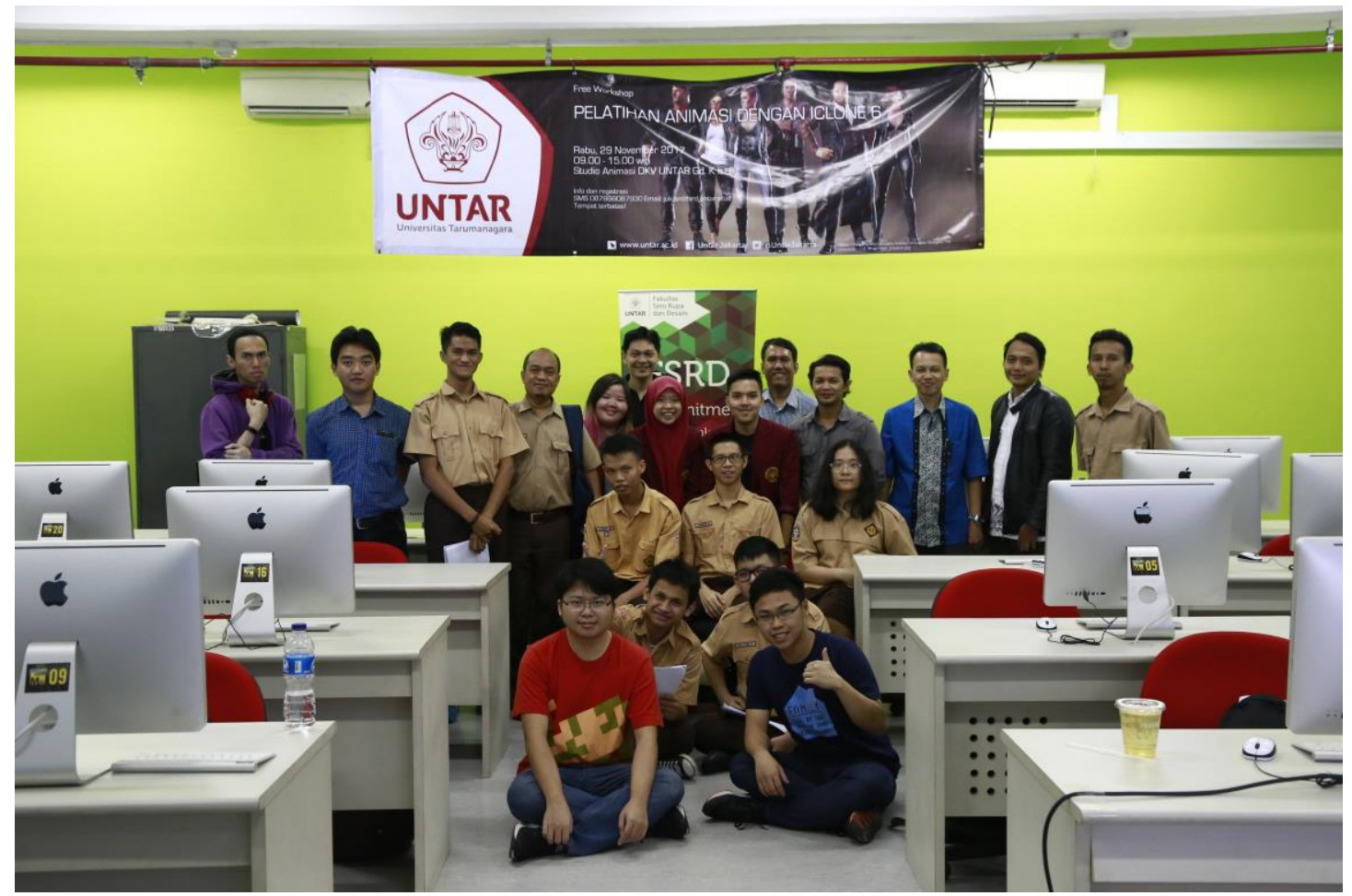

Gambar 8.. Foto bersama, tim workshop dan peserta dari sekolah Talenta.

\section{KESIMPULAN DAN SARAN}

Peserta pelatihan mampu mengikuti instruksi yang diberikan saat mempelajari software iClone 6 . Ada dua tahap yang diberikan di pelatihan ini. Tahap pertama pengetahuan tentang interface \& 
tools seperti menu create, content manager, scene manager, modify, visual setting, mini viewport, timeline membantu peserta memahami software ini. Tahap kedua latihan yang diberikan berupa pembuatan karakter (creating \& developing character, creating prop) diharapkan peserta dapat mempergunakan karakter yang ada di library atau memodifikasinya. Kekurangan kegiatan ini adalah waktu pelatihan yang lebih panjang agar peserta bisa bereksperimen dengan proyek masing-masing. Yang menarik ada kejadian dimana satu peserta siswa yang selalu menanyakan berkali-kali kapan waktu selesai pelatihan, ternyata siswa tersebut mengalami gangguan konsentrasi lebih tinggi dibandingkan siswa lain. Siswa tersebut dapat menyelesaikan program pelatihan yang kami berikan dengan baik.

\section{Acknowledgement}

Kegiatan ini didanai oleh DPPKM UNTAR dan atas terlaksananya kegiatan PKM ini, kami berterima kasih kepada Jap Tji Beng, PhD direktur PPKM UNTAR, Kurnia Setiawan, S.Sn., M.Hum. dekan FSRD UNTAR yang mendukung kegiatan ini. Juga terima kasih kepada Arini Soewarno ketua YPAC, dan Tri Yuli Prasetyo, S.Pd. Buat mahasiswa kami, Yohannes, Jessica Rien dan Silvi Salsabil yang telah membantu pelaksanaan PKM.

\section{REFERENSI}

iClone adalah produk dari Reallusion yang merupakan software 3D animation untuk produksi animasi profesional dalam waktu singkat untuk film, previz, animasi, game, content development, pendidikan dan seni dengan teknologi real time. Beberapa fitur software iClone antara lain; animasi karakter, animasi ekspresi wajah, karakter 3D, interior, eksterior, properti yang siap pakai, sistem pencahayaan yang intuitif, sistem kamera dengan standar Alexa. Red, Canon, tampilan visual yang realistik real time, import dan export aset 3D dengan mudah, dan akses mudah untuk mendapatkan ready to animate characters, motions, accessories and props (http://www.reallusion.com, 1 Agustus 2017). Saat ini pembelajaran yang menggunakan game berbasis 3D mendapatkan hasil yang positif bagi siswa yang menggunakannya (Yukselturk, Erman. 2018: 159). Jadi kemampuan animasi 3D sangat dibutuhkan saat ini.

Erin, J. N., \& Koenig, A. J. (1997). The student with a visual disability and a learning disability. Journal of Learning Disabilities, 30(3), 309-20. Retrieved from https://search.proquest.com/docview/194223934?accountid=38628

Handwerk, M. L., \& Marshall, R. M. (1998). Behavioral and emotional problems of students with learning disabilities, serious emotional disturbance, or both conditions. Journal of Learning Disabilities, 31(4), 327-38. Retrieved from https://search.proquest.com/docview/194224763?accountid=38628

Learning Disabilities Association of America. (2017). Types of Learning Disabilities, https://ldaamerica.org/types-of-learning-disabilities/1 Agustus 2017.

Reallusion Inc. (2018). What is Iclone?, http://www.reallusion.com, diakses1 Agustus 2018

The Coordinated Campaign for Learning Disabilities. What is a Learning Disability?, http://www.ldonline.org/ldbasics/whatisld, diakses 1 Agustus 2017 
UNESCO. (2009). Merangkul Perbedaan: Perangkat untuk Mengembangkan Lingkungan Inklusif Ramah terhadap Pembelajaran, buku khusus 3: Mengajar Anak-anak dengan Disabilitas dalam Seting Inklusif. IDPN Indonesia, Indonesia.

Yukselturk, Erman, et al. "Using Game-Based Learning with Kinect Technology in Foreign Language Education Course." Educational Technology \& Society, vol. 21, no. 3, 2018, p. 159+. Gale Virtual Reference Library, http://link.galegroup.com/apps/doc/A550300751/GPS?u=kpt03013\&sid=GPS\&xid=e51ab 376. Accessed 18 Aug. 2018. 